\title{
Chapter 10 \\ Healing Mainstream Health: Building \\ Understanding and Respect \\ for Indigenous Knowledges
}

\author{
Liz Rix and Darlene Rotumah
}

\section{Introduction: Our Story}

We first encountered one another around a decade ago when sharing an office at a rural health campus of The University of Sydney, where both of us were working on health research projects. From that first meeting we were intuitively drawn to each other, and soon discovered shared interests, and some surprisingly common perspectives and opinions on health services, seen with an Indigenous Australian lens. We were both employed in mainstream health at that time and had been longterm employees within the same local health district. Darlene, a proud Bundjalung woman from Booningbah (Fingal Heads), worked with her own people in her country as a counsellor in an Aboriginal health service within New South Wales Health. Liz, a non-Indigenous "outsider," worked as a specialist nurse in a busy specialist unit at a regional base hospital. Both of us have witnessed the multilayered institutional and individual racism that is the "normalised" experience of the majority of Indigenous Australians when trying to access mainstream health services. We both know from our own clinical and professional lives that racism is firmly embedded in health organisations and continues to dominate the treatment experience of Indigenous Australians.

It was our common perspective on these issues that were the origins of a strong relationship based on mutual respect. We share a passion for improving the journey and outcomes for Indigenous people forced to navigate a health system that is still perpetrating institutional racism and discriminatory practices. These issues are further exacerbated by the historical ignorance and lack of understanding of the majority of health professionals working within the mainstream system. We have since developed and nurtured our relationship based on a deeper shared understanding of the clinical and academic worlds where we have both worked. Our relationship is

L. Rix $(\bowtie) \cdot$ D. Rotumah

Gnibi College of Indigenous Australians, Southern Cross University, Lismore, Australia

e-mail: liz.rix@scu.edu.au

J. Frawley et al. (eds.), Cultural Competence and the Higher Education Sector, https://doi.org/10.1007/978-981-15-5362-2_10 
built on relational accountability and shared respect for Indigenous ways of knowing, being and doing. We agree on the urgent need for this kind of relationship between Indigenous and non-Indigenous Australians to be replicated in clinical encounters within mainstream health care environments.

We have learned much from one another as we spend time together in the space between our two worlds, as women, researchers and teachers. Darlene enabled Liz to obtain funding for her doctoral studies by providing a testimonial, outlining Liz's strengths in consulting with her community and building positive clinical and research relationships with her people as a nurse and academic. Liz has since reciprocated by providing informal guidance and support to Darlene as she works on her own doctoral studies. This is Liz's way of paying respect and thanks for Darlene's endorsement of her ability to work with her people as a health researcher.

A decade since we began to build our relationship, we found ourselves presenting the content of this chapter at a conference, Yarning Circle. The participants in this Yarning Circle were a mix of Indigenous and non-Indigenous educators, researchers and clinicians, gathered to explore the conference theme of cultural competence and the higher education sector. We both consider our bond and parallel worldviews as a practical model of how Indigenous and non-Indigenous people from all backgrounds can build strong, respectful relationships based on two-way learning and understanding.

\section{Some Background}

This chapter's opening story describes the co-authors' congruent lenses through which they viewed their experiences of working within mainstream health, where both have seen the daily challenges for Indigenous Australians when accessing hospital or mainstream health services, which are often alien and unwelcoming places to be (Durey, Wynaden, Davidson, \& Katzenellenbogen, 2012; Sherwood, 2013). Both authors have witnessed Indigenous Australians' experiences of distress and fear, often avoiding mainstream services, and routinely feeling disempowered and voiceless - a result of the ongoing impacts of colonisation (Paradies, 2016). Indigenous Australians' lives continue to be affected by historical and contemporary racism, deeply embedded social injustices and successive flawed government policies (Paradies \& Cunningham, 2009; Paradies, Harris, \& Anderson, 2008). Discriminatory attitudes of many white Australian health care professionals play a significant part in this fear and avoidance (Eades, 2000; Eckerman et al., 2010). This equates to systematic continuation of the dominant, racially tainted western lens on Indigenous Australians. This is occurring within a nation that is told by predominantly white, male politicians that Australia is a multicultural nation, and free of racism. This, however, cannot be further from the truth. In this nation, where deficitbased, racially-driven stereotyping remains systemic, blatant untruths are frequently flaunted in the federal parliament and mainstream media when any discussion of Indigenous Australians occurs (McCausland, 2004). While there is no universal 
Indigenous culture or language in Australia, there is a universal shared experience of Indigenous people encountering power differentials within health systems (Eckerman et al., 2010).

The deliberate state-led destruction of Indigenous communities, languages and culture has resulted in deep and transgenerational levels of trauma (Sheehan, Martin, Krysinska, \& Kilroy, 2009). This history underpins the "epidemic" proportions of chronic disease suffered by Indigenous people throughout first-world nations colonised by Europeans. Indigenous Australians experience some of the worst health disparities among colonised first-world nations, illuminating enormous gaps in social justice, equity and the social determinants of health (Anderson, Crengle, Kamaka, Palafox, \& Jackson-Pulver, 2006; Anderson \& Whyte, 2008; King, Smith, $\&$ Gracey, 2009). Despite this traumatic history, Indigenous Australians continue to fight for empowerment and self-determination, demonstrating high levels of cultural strengths, survival and resilience. Until mainstream health services remove their deficit-focused, problematic spotlight on all things Indigenous in this nation, there can be little progress. Indigenous academics have been calling for years for the "writing back against the deficit position, in itself a health-promoting exercise" (Arabena, Rowley, \& MacLean, 2014, p. 317).

Despite the election of several Indigenous people to the federal parliament, there remains no prioritisation of Indigenous voices in this nation's parliament. This is a strong contributor to Australia remaining a racially dysfunctional and disturbed nation (Johnson, 2018; Sanders, 2018). Ignorance and denial of the history of the colonisation of this land remain the "norm" for many white Australians (Higgins \& Wellington, 2018), and this history is a continuum of white privilege that still plays out in the form of institutional racism (Durey, Thompson, \& Wood, 2012; Henry, Houston, \& Mooney, 2004). In 2017 the Uluru Statement from the Heart (Referendum Council, 2017) called for an Indigenous voice in the Australian Constitution but was swiftly dismissed by the Federal Government. It has, however, been strongly endorsed by the Australian Medical Association (AMA) in an anti-racism statement:

Racism can occur in both direct and indirect forms, including casual or everyday racism and implicit or unintentional racism, and can be experienced by a patient from their healthcare provider, by a healthcare provider from their patient, or between healthcare providers. (Johnson, 2018, p. 7)

The above quote, and the AMA's support for the Uluru Statement from the Heart, while encouraging and positive, is indicative of the current tensions around mainstream health service delivery to Indigenous Australians. We present our relationship and relational accountability as a metaphor for what needs to change within mainstream services, and in the policy and services delivery context (Wilson, 2008). This is not a research or policy-based piece of writing; instead, we aim to encourage mainstream services and individual health care professionals to think and act beyond the level of "address policy and tick the box" outcomes, when engaging with Indigenous Australians within mainstream health organisations. We discuss the challenges of teaching non-Indigenous undergraduate health students the essential nature of developing critical self-reflection and gaining insight into the unconscious bias their own 
white privilege provides. We discuss solutions to the ongoing systemically embedded racism within health care organisations, via a model of health care services for Indigenous Australians that includes Indigenous Australians themselves as the "experts" in their own peoples' health and wellbeing.

\section{Two-Way Understanding Through Yarning Circles at the Cultural Interface}

Yarning Circles are an Australian Indigenous way of communicating within a group, and also an Indigenist method of communication and discussion (Dean, 2010; Mills, Sunderland, \& Davis-Warra, 2013; Walker, Fredericks, Mills, \& Anderson, 2013). Yarning Circles "provide the equal sharing place where deep equity can be achieved" (Sheehan, 2011, p. 70). Yarning Circles provide a space where each person can speak in turn without interruption, with participants within the Circle requiring "deep listening" skills. Yarning Circles create a respectful and effective way to prioritise Indigenous voices within any communication between Indigenous and non-Indigenous group members (Fredericks et al., 2011).

This work has emerged from a Yarning Circle entitled Healing Mainstream Health, conducted by the co-authors at a 2018 conference held by the National Centre for Cultural Competence (NCCC), University of Sydney. The challenges of building respectful "two way" therapeutic relationships between Indigenous people and nonIndigenous health care professionals were explored. Our Yarning Circle recommended the inclusion of Indigenous ways of knowing, being and doing in mainstream health institutions, as the way forward in reducing health inequities and the reluctance many Indigenous Australians have about engaging with biomedical care and treatment.

This Yarning Circle enabled the co-author's voices to be heard at the cultural interface, where a mix of Indigenous and non-Indigenous participants engaged within the Circle. The term cultural interface was coined by an Indigenous Australian scholar and refers to "the intersection of the Western and Indigenous domains" where Indigenous and non-Indigenous knowledges intersect (Nakata, 2002, p. 284) The combination of a Bundjalung and white woman conducting the Yarn was a working example of blending western and Indigenous perspectives, and knowledge in practice. This approach aimed to apply a culturally safe lens to prioritising Indigenous voices and is a key Indigenist communication tool in the research and health services context (Bessarab \& Ng"andu, 2010; Jennings, Bond, \& Hill, 2018).

According to Indigenist philosophy, and the principles of relational accountability, the co-creation of new knowledge is a relational exercise that cannot occur with an individual in isolation. Just as in Indigenous cultures, the land is not owned by one person, an individual cannot own new knowledge and must acknowledge those they have worked or collaborated within the discovery of that new knowledge (Rix, Barclay, \& Wilson, 2014a, 2014b; Wilson, 2008). Our opening story describes the 
power of working together to create two-way understanding across our two cultures. Here, we apply our metaphor to the creation of new knowledge, and also to our shared experience and understanding of the challenges Indigenous people face on a daily basis when trying to access mainstream health services.

Indigenous people, when accessing mainstream health services and when under the care of white health care staff, (particularly when hospitalised) frequently experience high levels of disempowerment, judgement and discrimination (Aspin, Brown, Jowsey, Yen, \& Leeder, 2012; Durey, Thompson, \& Wood, 2011). Indigenous scholars have always known that an awareness and understanding of Indigenous history, culture and protocols is essential, when preparing health students to develop a culturally based and respectful way of working with Indigenous people under their care (College of Nurses Aoterea, 2010; Downing, Kowal, \& Paradies, 2011; Thackrah \& Thompson, 2013; Westerman, 2004).

In order to provide an environment where health care and treatment incorporates cultural understanding and respect, undergraduate health students must be provided with extensive education about the realities that have created the current health disparities suffered by Indigenous people in Australia.

I don't think we could overestimate how much colonisation, invasion, disrespect, illegal acts, it's immeasurable how much damage that's done and if you damage my grandmother, if you damage my mother you damage me, you know. It is like that damage, that hurt, you carry through. (Wilson, Kelly, Magarey, Jones \& Mackean, 2016, p. 8)

Understanding by the mainstream health workforce of the historical, political and social disadvantage underlying contemporary causes of Indigenous Australian peoples' health disparities is central to shifting the institutional barriers that stand in the way of achieving health and social equity (Anderson \& Whyte, 2008; Awofeso, 2011; Coffin, 2007; Sherwood, 2009). This learning must come from a position of strength and resilience, where students are forced to scrutinize and confront the biomedical focus and negatively tainted lens that problematises not just health issues, but all conversation relating to Indigenous Australians (Jackson, Power, Sherwood, \& Geia, 2013).

I think they need to get back to school ... learn about Aboriginal issues and have cultural values about 'em, Aboriginal cultural values. Because half the time their attitude towards Aboriginal issues and values keeps Aboriginals away. Sometimes Aboriginals don't want to go and listen to 'em, they stay away and at the end of the day the Aboriginal suffers. [Camilleroi Elder, 2011] (Rix, Barclay, Stirling, Tong, \& Wilson, 2015)

Indigenous nurse and scholar Juanita Sherwood contends that the poor health status of Indigenous Australians is maintained through "victim" blaming and "othering" in a nation where "whiteness" is the norm. This normalising of a problematic approach "serves to reinforce the practice of othering or .... problematising the marginalized uncooperative element of society" (Sherwood, 2009, p. S25).

The actual teaching used to deliver this learning needs to incorporate not just historical and contemporary facts, but also Indigenous ways of knowing, doing and learning. These may be storytelling and yarning styles of interaction within the teaching, by Indigenous and non-Indigenous teachers. Both co-authors have 
practical teaching experience, in a number of educational settings, of how students value the learning they gain from both Indigenous and non-Indigenous educators working together in the classroom. An appropriate mix of stories told by Indigenous Elders, scholars and health care professionals, along with anecdotal stories from non-Indigenous clinicians who have worked closely with Indigenous people at the mainstream health "coalface," can provide a practical, yet culturally informed and driven education experience (Virdun et al., 2013). Just as the opening story in this chapter presents our relationship based on respect for one another's worldviews, and culture as metaphor for working together with two-way understanding within mainstream health, this can be extended to the classroom in the context of teaching Indigenous health and culturally shaped care and treatment.

\section{Critical Self-Reflection ... It can't Be Faked}

How can we expect health students to attempt to use an alternative lens on the world when many have no concept or awareness of their own cultural lens or privilege as a white Australian?

Encouraging students to reflect on their own white or western privilege is crucial in the journey towards creating culturally safe and accessible health services (Durey, Thompson, \& Wood, 2010). The impact of urging students to face (often for the first time) their previously unconscious assumptions of privilege, as members of the dominant population in this country, is a fraught task for educators. Further, students are then required to reflect even more deeply, to unpack how these unconscious assumptions impact and influence their own professional lens and practice, and how their practice then impacts on their clients. Urging students to go beyond the level of describing deficit-focused literature, in order to address what is often framed as the "Aboriginal problem," within assessment tasks, and stimulating a genuine desire to build strong therapeutic relationships based on two-way understanding and respect, is indeed a challenge in contemporary Australia. Teaching this material is not for the faint-hearted and can be a very stressful experience.

Anecdotal teaching and clinical experiences have taught the co-authors that a number of undergraduate health students approach the prospect of studying Indigenous health with the expectation that it will require a minimal academic lens, and even with a patronising "tick the box"-to-get-the-degree approach. There can be a misconception that it will be an easy unit in which to achieve a good grade. The obvious question here is "why is this so?" Why do students make this false assumption? We propose the concept that a powerful tool to assist in changing this may well be increasing the Indigenous and non-Indigenous teaching team approach, and further developing teaching strategies that can highlight and showcase these positive intercultural relationships. Students may then witness the power of collegial and collaborative teamwork in a classroom setting. Experiencing this may also assist students in the critical reflection required to examine their own relationships with students, co-workers, clients and so on. 
The realisation that Indigenous Education is actually everyone's business has recently become clear: everyone is now required to take up this responsibility ... Therefore, respectful collaboration between Indigenous and non-Indigenous academics remains crucial. (Virdun et al., 2013, p. 4)

\section{Students' Reality Check ...}

When students first begin to engage with some historical and contemporary truths about the state of Indigenous people's health, they soon discover that it is a challenging and confronting topic.

Basically, we are not very good about knowing our own history. Aboriginal people know theirs extremely well. You know, [people ask] "why did we have to say sorry, why do they keep going on about it?" And whilst we acknowledge we need to move forward, we can't forget the past. (Wilson et al., 2016, p. 8)

To succeed in understanding and engaging with this topic, students are required to develop their critical thinking skills and apply critical self-reflection to their own culture. The majority of undergraduate students face very real difficulties in moving from simply absorbing and repeating facts at the school level, to critically examining and synthesising literature and learning at university. In view of this, how much more of a challenge is it to ask students new to academia, to critically examine their own culture and worldviews, and how these influence their professional practice when working with Indigenous clients? This challenge is further complicated when students arrive at the classroom with pre-existing racist or discriminatory attitudes.

Then there is the need to respect differences and acknowledge that there is another worldview that must be part of any successful therapeutic relationship, and this subject matter can result in a reactive and negative response from some students. Students then tend to react in a number of ways to being taught that they are members of the colonising, dominant cultural group. Their white privilege can kick in, via angry and negative reactions, when being taught some of the truths about the colonisation of this country. This reactive approach to their learning emerges in a number of ways, with students sometimes targeting the lecturer or the material used. The majority, however, refrain from voicing their anger or disbelief when exposed to the ugly truth of the violent history of this country, preferring instead to complain anonymously in formal teaching evaluations at the end of the session. It would appear that students looking through a lens of racism prefer to be covert, with their only focus being a "good grade" and ticking the box as a culturally safe health care professional. These students, however, become complicit in the continuation of institutional racism towards Indigenous Australia, therefore contributing to the gap in health and wellbeing between Indigenous and other Australians (Australian Institute of Health and Welfare, 2019). 


\section{Complexity of Terms and Culturally Respectful Care}

Health systems and organisations need to progress beyond the current tokenistic approach to cross-cultural encounters still evident in many services. The use of medical jargon, and complex profession-based terms and language, firmly embeds and reinforces power imbalances between Indigenous people and health care professionals (Cass et al., 2002).

When the doctors and staff explain things to the Aboriginal patient, I found what they do, they talk in university words, big jaw breakers, instead of just talking plain English so they can understand it [Bundjalung Elder, 2011] (Rix, Barclay, Stirling, Tong, \& Wilson, 2014a, 2014b)

The current confusing range of culturally focused terms and theories-for example, cultural security, cultural sensitivity, cultural humility, cultural awareness - can add an unnecessary level of complexity to the challenges of undergraduate health students developing an empathetic cultural lens. It may be argued that this may be yet another example of the systemic and policy complexity which is inadvertently contributing to further compound and reinforce ongoing unequal power relationships within health care encounters.

In the words of remote practice nurse Sarah Ong:

Endless spoken words or conversations consisting of medical jargon are not necessary to develop or maintain a therapeutic relationship, however, both parties spending time listening, accepting and supporting each other is essential. (Ong, 2012, p. 33)

This remote nurse's words demonstrate her dedication to the principles of cultural safety, and her ability to work across the two worldviews. Just as we authors are learning from one another in the professional space between Indigenous and nonIndigenous culture, Sarah is applying the principles of developing therapeutic relationships in her clinical practice, by way of listening to, supporting and respecting the diversity of her Indigenous client's worldviews.

\section{Negative Focus of Mainstream Media: What the Hell is Cultural Safety Anyway?}

Cultural safety for Indigenous Australians has only recently been added to the Nurses and Midwives Code of Conduct (NMBA, 2018). This news, however, triggered a series of vehement racial attacks from right political factions within the health care industry and mainstream media. In these attacks, broadcast nationally by a mix of commercial television and radio networks, a number of blatant untruths were stated as fact. These included a false claim that white nurses must "declare" their white privilege to Indigenous people before being allowed to care for them (ABC, 2018).

Please tell me I'm wrong. As I understand it, this new code of conduct for nurses in Queensland requires obviously white nurses to announce they've got white privilege before they can 
look after patients of an Indigenous or Torres Strait Islander background. Am I right there? (Credlin, 2018)

Several radio journalists took this further during a blatantly racist rant about the addition of cultural safety to the Nurses Code of Conduct which showcased some ignorance and bias. Andrew Bolt parodied an end of life hospital scene, stating:

What about if they're just within seconds of dying and the nurse has to fling themselves into action, but they have to stop, before, while they just announce their white privilege, oh too late. (ABC, 2018)

When discussing the Nurses Code, radio presenter Michael McLaren showcased his lack of research skills, and ignorance, by stating: "This all sounds ridiculous to me. What the hell is cultural safety anyway? No one's ever heard of it" (ABC, 2018). This style of media sadly confirms the lack of progress in addressing the institutional racism and discrimination that remain endemic within health care in this nation. Further, it reinforces the coloniser's negative and racially tainted lens on Indigenous Australians and their culture (McCausland, 2004).

This is an example of mainstream media driving and reinforcing the negative stereotyping of the "Aboriginal problem" in this nation. This kind of reporting ensures these attitudes remain the commonly accepted view of white Australia. The Nursing Code of Conduct simply states:

Cultural safety is recognising the ways you can provide care that meets Aboriginal and/or Torres Strait Islander peoples' needs and reflect on the ways that your own culture and assumptions might impact on the care you give. (NMBA, 2018)

These racially-focused factions of the media, however, used this long-overdue addition to the Nursing Code of Conduct to confirm the "Aboriginal problem" in the minds of many Australians. Students and practising health care professionals must be made aware of, and reflect on, this style of journalism if they are to develop a deeper understanding of race relations in this country. This media-fuelled racism remains a significant barrier to the provision of culturally competent and respectful care and treatment for Indigenous Australians.

\section{Evaluation of Cultural Competence/Safety: Impossible from a Health Services Lens?}

The cultural differences between Indigenous and non-Indigenous Australians have been described as a cultural "chasm" that severely handicaps accessible and acceptable health services (Thomson, 2005). Research has shown cultural competence training outcomes remain poor, with experiences of institutional and individual racism still the norm for Indigenous Australians engaging with mainstream services (Franks, 2011; Westwood \& Westwood, 2010). This highlights the urgent need for health care organisations to critically examine their policies and practices, for embedded racism and discriminatory treatment of Indigenous Australians (Downing 
et al., 2011; Thackrah \& Thompson, 2013). A systematic review of interventions aimed at improving cultural competence in health care found that studies commonly lacked a standardised and validated research instrument that can measure cultural competence (Truong, Paradies, \& Priest, 2014). It is of concern that there is no available evaluation of the cultural competence of individuals or health care organisations from the perspective of the consumers, Indigenous Australians; and the work of Indigenous and non-Indigenous scholars over the past decade has clearly shown the lack of effective evaluation methods and tools to achieve this (Franks, 2011; Westwood \& Westwood, 2010). In any other context, evaluation of service delivery from the perspective of the consumer-which is assumed in the context of patient-centred care models (Kitson, Marshall, Bassett, \& Zeitz, 2013)—would seem to be a "no brainer." There remains, however, no impetus for Indigenous consumers, their Elders and community leaders to determine effective evaluation of their peoples' treatment within health organisations. This is yet a further example of mainstream health's lack of motivation to increase Indigenous self-determination and empowerment.

A 2011 study by an Indigenous Australian nurse sought to evaluate the effectiveness of cultural awareness training for all staff working in her health service (Franks, 2011). This quantitative study used a questionnaire to elicit the attitudes and beliefs of health staff who had accessed a one-day cultural awareness training program provided by New South Wales Health. While the findings showed some improvements in the cultural awareness levels of staff, the findings showed little or no motivation of individuals or health organisations to move beyond mere awareness of cultural differences, to improving the cultural competence of staff and organisational policies and practices (Franks, 2011). A major strength of this work was that the measurement instrument was based on the lived experience of Indigenous clients accessing the health service. In addition, the Indigenous nurse-author used what she terms the Aboriginal "Culture House" (see Fig. 10.1) as a metaphor for a "framework or lens through which we can consider the need for, the history of, and current approaches to addressing cultural differences in provision of health care services" (Franks, 2011, p. 10). The author uses this Culture House metaphor to illustrate the complexity and interdependence of interrelated aspects of, and terms used for, addressing cultural differences. She explains that if any part of the structure is overlooked or omitted, the house becomes unstable and untenable.

In order to build a complete picture of the most important aspects combined into an overall framework, those aspects have been set into the metaphor of a Culture House where (a) is a path leading to a more complex set of interdependent elements, which represents cultural awareness; (b) is the foundation, which represents building further on cultural awareness and developing into cultural sensitivity; (c) and (d) are the walls of cultural safety and cultural security, building on the simpler yet essential foundations; (e) is the ceiling, which represents Cultural Respect; and (f) is the roof, which represents cultural competence: the house is now complete and "liveable" (Franks, 2011 p. 8).

Until there is a validated tool that enables evaluation of cultural competence of individuals and organisations, from the perspective of Indigenous people (the consumers), it remains doubtful that mainstream health can provide sustained and 


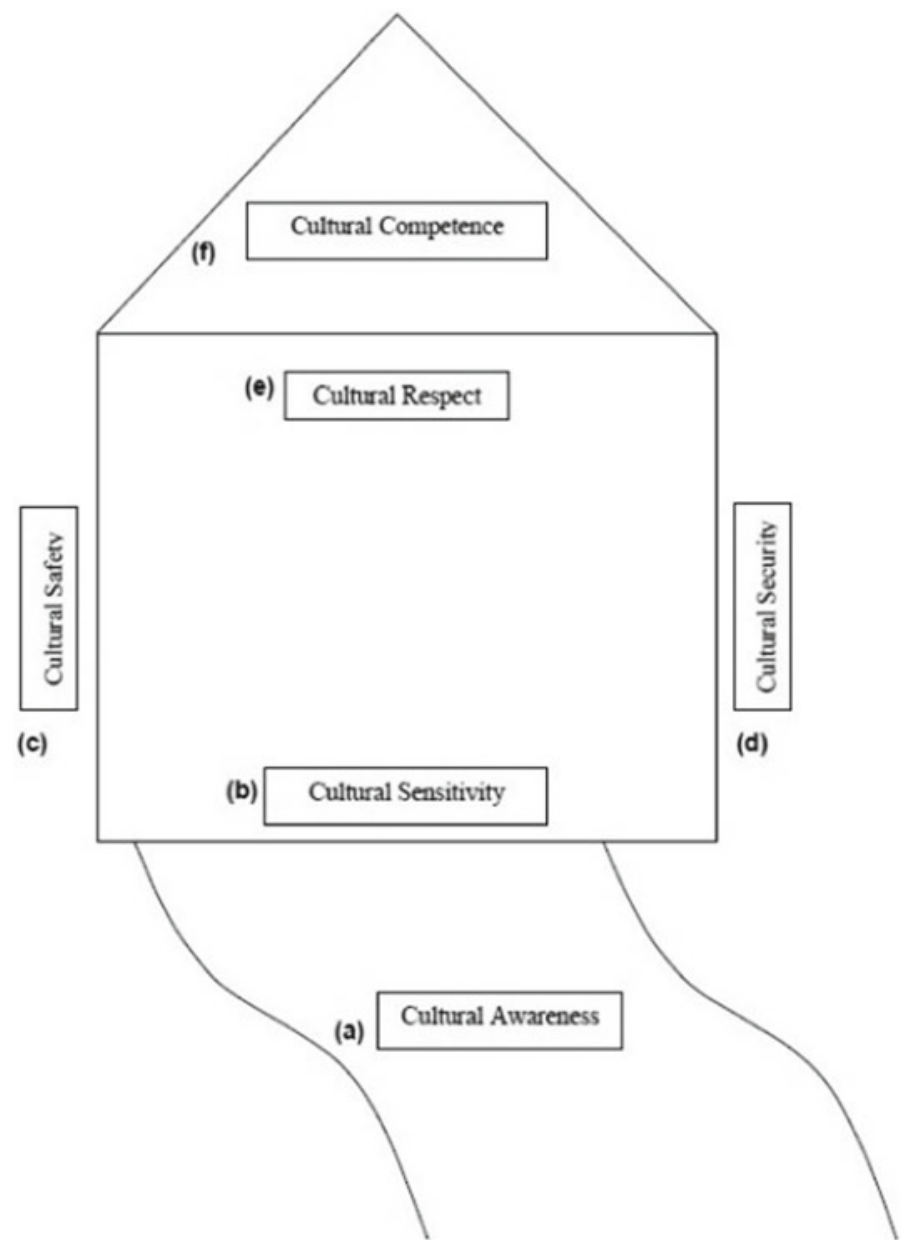

Fig. 10.1 The Aboriginal "culture house"- a metaphor for the complexity and interdependence of related aspects of addressing cultural differences (Franks, 2011 p. 9)

auditable, culturally competent and safe care to Indigenous Australians (Bronwyn Fredericks, 2010; Fredericks, 2003).

\section{Indigenous Health Care Professionals: A Culturally Safe and Competent Workforce}

The Australian Government and universities must ensure that more Indigenous doctors and nurses graduate and encourage them (but not oblige them) to work in delivering culturally appropriate services to their communities. Breaking down the barriers to access for 
Aboriginal and Torres Strait Islander people will increase the numbers attending mainstream primary health care services and result in significant improvements in Indigenous morbidity and mortality. (Hayman, White, \& Spurling, 2009)

Mainstream health must prioritise a sustained increase in the Indigenous workforce in order to demonstrate their commitment to closing the health and wellbeing gap between Indigenous and non-Indigenous Australians (Duff, 2018; National Aboriginal and Torres Strait Islander Health Workers Association, 2018). This requires health systems to prioritise the delivery of culturally safe and competent care within mainstream policy and practice, and the prioritisation of Indigenous Knowledges (IKs). This is clearly documented in the overabundance of government documents and policies (Australian Government Department of Health, 2017; Australian Health Ministers' Advisory Council, 2017). However, this positive rhetoric is still being overlooked or ignored at the "coalface" of service delivery (Eckerman et al., 2010; Taylor \& Guerin, 2014). The question here is: how can government policies and research reflect genuine and respectful engagement by the dominant western and biomedical power brokers? This will not occur until governments and mainstream health organisations prioritise genuine translation of research and policy into practice, thereby moving beyond positive rhetoric and merely being seen to address key performance indicators.

Indigenous health care professionals need to be respected and promoted as the key to achieving the highest level of cultural safety and competence in the Australian health care system. They are the pinnacle of culturally shaped and competent health services delivery for Indigenous Australians (Sherwood et al., 2015; Stuart \& Nielsen, 2011).

You know how it is in Aboriginal communities; nobody goes by their real name. They go by their nickname. To have that knowledge, that's like a language within itself, if you know the lingo or the mob then you are half way there. (Stuart \& Nielsen, 2011, p. 98)

This is well known by Aboriginal community controlled health care organisations where Indigenous workforces are the drivers of clinical services (National Aboriginal Community Controlled Health Organisations, 2016). The strategy of Indigenous health care professionals and organisations of positioning Indigenous health care professionals at the forefront of services is key to improving Indigenous Australian peoples' health and wellbeing; and this was well documented in 1989 (National Aboriginal Health Strategy Working Party, 1989). This is a typical example of the lack of prioritisation of these issues by successive governments despite evidence showing how those issues can be addressed.

\section{The Shadow of Racism ... Always There}

Indigenous health care and medical professionals have profound insight into the challenges facing Indigenous people when accessing health care. Their experiences of interaction with their fellow non-Indigenous colleagues mirror the experience of 
Indigenous patients within health care systems. Indigenous clinicians live with racial vilification and blatant racism within their chosen disciplines and workplaces. The current president of the Australian Indigenous Doctors' Association documented this in his discipline's magazine, where he discussed the lack of awareness in the medical profession of what it is to be Aboriginal Australian suffering endemic institutionalised racism in culturally unsafe environments (Rallah-Baker, 2018a).

My own dealings with blatant racism, degradation, training delays, bullying, harassment and racial vilification are unfortunately considered an unremarkable experience amongst my Indigenous medical brethren. To many of us, racially motivated workplace violence is the norm. Institutionalised racism, unconscious bias and cultural insensitivity might sound like buzzwords people kick around, but they are real, and their impact is real. (Rallah-Baker, 2018a)

One of the co-authors recently taught an academically outstanding Indigenous midwifery student during her undergraduate degree, witnessing this student's passion for working with Indigenous women throughout their birthing journey. This student, however, experienced a confronting form of "culture shock" while on a clinical placement near the end of her degree. She found herself traumatised by witnessing the distress and pain of her own people when forced to birth in a regionally-based hospital, where the white staff were openly disrespectful and demonstrating minimal cultural competence, or cultural safety, in the hospital birthing environment. Other Indigenous health care professionals experience similar trauma as they attempt to study and work within mainstream health and education facilities (Gorman, 2017). Not only are they made acutely aware that culturally unsafe places, hospitals and mainstream health services remain, but Indigenous health care students and professionals themselves experience racism and discriminatory treatment by their peers and colleagues on a daily basis (Rallah-Baker, 2018b). A recent study of the experiences of Indigenous health workers enrolled in a Bachelor of Nursing degree commonly found both overt and covert racism directed towards them by their white student peers. "There's still a lot in the white nursing students that make negative comments about Indigenous people and you hear it in class, it makes you feel like walking out" (Stuart \& Gorman, 2015, p. 35).

Indigenous nursing students regularly experience negativity and racist judgements by their fellow white nursing students:

They said, "No good putting them in a house, they will knock it down and actually start fires with the wood." I said, "Look you know I'm Aboriginal, I actually own my own home." It just makes you wonder when they actually do become registered nurses how they're going to treat Aboriginal people on the wards. (Stuart \& Gorman, 2015, p. 35)

While these attitudes remain the norm, it is obvious there is still much work to be done to assist non-Indigenous clinicians to overcome their own unconscious bias when working with Indigenous Australians (Rallah-Baker, 2018b). This is critical to enabling respectful therapeutic relationships with their Indigenous colleagues and patients. Conversations about racism remain a very contested space within the health care context. In the words of Indigenous doctor Kristopher Rallah-Baker, "We live in a country where it is almost taboo to talk about racism" (Rallah-Baker, 2018b). 


\section{We Need to Find Solutions Together at the Cultural Interface}

Government health policies cite culturally competent health professionals as vital to "Closing the Gap." While using positive terms of reference and rhetoric, these policies-based on the dominant western biomedical perspective-continue to struggle to deliver tangible improvements to health outcomes for Indigenous Australians (Australian Health Ministers" Advisory Council, 2017). One question that is often asked by Indigenous people is, "how can the dominant group that, just by its very existence, is the cause of the current cultural chasm between Indigenous Australians across all social determinants of health, be charged with finding the solutions?" (Sherwood, 2010).

We, the co-authors, argue that part of the solution lies at the clinical coalface of mainstream health services in the building of strong and respectful relationships, as per our story metaphor. Mainstream health organisations and clinicians acknowledging and respecting Elders, community members and all Aboriginal health staff, as the experts in their people's health and wellbeing, is part of that solution. NonIndigenous health care professionals and researchers critically reflecting on their own culture, as the dominant culture, can support the two worldviews to work together, free of the power imbalances and racism that remains embedded systemically in the dominant biomedical space.

Combining biomedical and Indigenous perspectives has the potential to provide care and treatment for Indigenous Australians that is medically and culturally rigorous and safe, in a very real and practical way, rather than just being a "tick the box" exercise that is, in effect, a show of politically correct "othering" of Indigenous people seeking health care (Sherwood, 2009). This may play out as simply a nurse asking a hospitalised Indigenous patient about their health care preferences; the nurse may then consult with family or Elders about ways to better support that client while in hospital. The nurse has demonstrated culturally safe care by seeking the advice of those with intimate knowledge about the client and their family, cultural norms and preferences (Rix, Moran, Kapeen, \& Wilson, 2016). Simply seeking a patient's cultural preferences regarding, for example, the gender of their caregivers, and those who are sharing their room while hospitalised, can begin a positive therapeutic relationship and reduce feelings of vulnerability (Secretariat of National Aboriginal and Islander Child Care Australia, 2012).

\section{Indigenous Ways of “Knowing, Being and Doing” Healing}

When we put [western medicine and traditional Yolngu healing] together, we strong-both feet strong. We can see with a clear mind. Stand strong together. (Oliver, 2013, p. 6)

Despite overwhelming evidence that countering the profound impacts of colonisation requires reconnecting people to culture, country and traditional healing methods, successive governments remain resistant to acknowledging the potential healing 
power of inclusion of IKs. Indigenous scholars, Elders and communities have been urging policy-makers and governments to access IKs and expertise for generations. Inclusion of traditional Indigenous medicine and culture in all aspects of health promotion and service delivery for Indigenous people and increasing collaboration between the biomedical model and Indigenous ways of knowing, can reduce power imbalances and contribute significantly to decolonising health services delivery (Aspin et al., 2012; Sherwood, 2013).

For the high numbers of Indigenous Australians impacted by colonisation, healing occurs by way of reconnection to "Country," family and culture (Kirmayer, Dandeneau, Marshall, Phillips, \& Williamson, 2011; Maher, 1999; Poche Indigenous Health Network, 2016). A form of cultural healing occurs when colonised Indigenous people can reconnect to Indigenous ways of knowing, being and doing. This may be through dance, art, learning traditional ways, or sitting down with Elders and listening to traditional stories (Aboriginal and Torres Strait Islander Healing Foundation, 2013). As Kombumerri Elder Auntie Mary Graham states:

Although Indigenous people everywhere are westernised to different degrees, Aboriginal people's identity is essentially always embedded in land and defined by their relationships to it and to other people. (Graham, 2008, p. 187)

Indigenous culture has never been static; however, communities have always placed the wellbeing of their people and country at the centre of their worldview (Morgan, Slade \& Morgan, 1997; Hunt, 2013), enabling evolution and adapting to change with resilience.

We need to gain an understanding of the issues surrounding Indigenous health, culture and survival. This knowledge is important for the future of health provisions in this country. (Merritt, 2007, p. 12)

Mainstream health can acknowledge that the inclusion of IKs and expanding the biomedical understanding of Indigenous health and wellbeing, is the missing component in closing the current health gap (Hunt, 2013; Durie, 2004; Poche Indigenous Health Network, 2016). Combining biomedical and Indigenous ways of knowing and healing can not only assist in closing the current health gap, but a fusion of health and healing strategies from both worlds can contribute to breaking down power imbalances within mainstream health and provide Indigenous Australians selfdetermination and culturally safer health services (Durie, 2004). If mainstream health organisations take this path, there are many potential flow-on effects towards Indigenous Australians' social determinants of health, including employment, education, social capital and, most importantly, racism.

Mainstream initiatives that engage with Aboriginal cultural practice, philosophy, spirituality and traditional Aboriginal medicines are examples of how to enact the theoretical concept of Indigenous Knowledges into reality and practice. However, there are too few examples of where this is happening in a meaningful and enduring way. (Poche Indigenous Health Network, 2016) 


\section{Conclusion}

The co-authors have offered their relationship and the principles of relational accountability as a metaphor for how mainstream services can create more culturally comfortable and safer treatment and care environments for Indigenous people seeking their services. Mainstream health organisations must acknowledge and address the systemically embedded institutional racism that drives the experience of Indigenous Australians when accessing health care services. Until this occurs, there can be little closing of the current health and wellbeing gap between Indigenous and non-Indigenous Australians. We have unpacked some of the challenges of teaching undergraduate health students to reflect on the dominance of their western culture. This is crucial if students are to build positive therapeutic relationships with Indigenous people based on two-way understanding. Respect for and inclusion of IKs and traditional healing is crucial if mainstream health itself is to heal from over two centuries of the racial and cultural exclusion of Indigenous Australians from equitable access to health care services.

\section{References}

Aboriginal and Torres Strait Islander Healing Foundation. (2013). Growing our children up strong and deadly: Healing for children and young people. Retrieved from https://healingfoundation. org.au/wordpress/wp-content/files_mf/1369185755GrowingourChildrenupsinglesfeb2013.pdf

Anderson, I., Crengle, S., Kamaka, M. L., Chen, T.-H., Palafox, N., \& Jackson-Pulver, L. (2006). Indigenous health in Australia, New Zealand, and the Pacific. Lancet, 367(9524), 1775-1785.

Anderson, I., \& Whyte, J. D. (2008). Populations at special health risk: Indigenous populations. In International Encyclopedia of Public Health (pp. 215-224). Oxford: Academic Press.

Arabena, K., Rowley, K., \& MacLean, S. (2014). Building evidence about effective health promotion in Aboriginal and Torres Strait Islander communities. Australian Journal of Primary Health, 20(4), 317-318. https://doi.org/10.1071/PYv20n4_ED

Aspin, C., Brown, N., Jowsey, T., Yen, L., \& Leeder, S. (2012). Strategic approaches to enhanced health service delivery for Aboriginal and Torres Strait Islander people with chronic illness: a qualitative study. BMC Health Services Research, 12, 143. https://doi.org/10.1186/1472-6963$12-143$

ABC. (2018). White privilege outrage. Mediawatch. Retrieved from https://www.abc.net.au/med iawatch/episodes/white-privilege-outrage/9972296.

Australian Government Department of Health. (2017). Aboriginal and torres strait islander health workforce. Retrieved from https://www.health.gov.au/internet/main/publishing.nsf/Content/wor $\mathrm{k}-\mathrm{ab}$.

Australian Health Ministers' Advisory Council. (2017). National aboriginal and torres strait islander health workforce strategic framework 2016-2023. Retrieved from https://www.health. gov.au/internet/main/publishing.nsf/Content/4A716747859075FFCA257BF0001C9608/\$File/ National-Aboriginal-and-Torres-Strait-Islander-Health-Workforce-Strategic-Framework.pdf.

Australian Institute of Health and Welfare. (2019). National indigenous reform agreement. Canberra: Australian Government. 
Awofeso, N. (2011). Racism: A major impediment to optimal Indigenous health and health care in Australia. Australian Indigenous Health Bulletin, 11(3).

Bessarab, D., \& Ng'andu, B. (2010). Yarning about yarning as a legitimate method in Indigenous research. International Journal of Critical Indigenous Studies, 3(1), 37-50.

Cass, A., Lowell, A., Christie, M., Snelling, P., Flack, M., Marrnganyin, B., \& Brown, I. (2002). Sharing the true stories: Improving communication between Aboriginal patients and healthcare workers. Medical Journal of Australia, 176, 466-470.

Coffin, J. (2007). Rising to the challenge in Aboriginal health by creating cultural security. Aboriginal and Islander Health Worker Journal, 31(3), 22-24.

College of Nurses Aotearoa (NZ) Inc. (2010). Cultural safety stories. Retrieved from https://www. nurse.org.nz/cultural-safety-stories.html.

Credlin, P. (Presenter). (2018, March). Skynews. [Television broadcast]. Sydney, Australia: Skynews.

Dean, C. (2010). A yarning place in narrative histories. History of Education Review, 39(2), 6-13.

Downing, R., Kowal, E., \& Paradies, Y. (2011). Indigenous cultural training for health workers in Australia. International Journal for Quality in Health Care, 23(3), 247-257. https://doi.org/10. 1093/intqhc/mzr008

Duff, D. (2018). Deadly Choices: Growing our future aboriginal and torres strait islander health workforce. Paper presented at the National Conference on Indigenous Health Workforce: Moving beyond the frontline, Brisbane.

Durey, A., Thompson, S. C., \& Wood, M. (2010). Reducing racism in Aboriginal healthcare: Where does cultural education fit in? Australian and New Zealand Journal of Public Health, 34(S1), S87-S92.

Durey, A., Thompson, S. C., \& Wood, M. (2011). Time to bring down the twin towers in poor Aboriginal hospital care: Addressing institutionalised racism and misunderstandings in communication. Journal of Internal Medicine, 42. https://doi.org/10.1111/j.1445-5994.2011.02628.x.

Durey, A., Wynaden, D., Thompson, S. C., Davidson, P. M. B., D, \& Katzenellenbogen, J. (2012). Owning solutions: A collaborative model to improve quality in hospital care for Aboriginal Australians. Nursing Inquiry, 19(2), 144-152. https://doi.org/10.1111/j.1440-1800.2011.005 46.x.

Durie, M. (2004). Understanding health and illness: Research at the interface between science and indigenous knowledge. International Journal of Epidemiology, 33(5), 1138-1143. https://doi. org/10.1093/ije/dyh250

Eades, S. J. (2000). Reconciliation, social equity and Indigenous health. Medical Journal of Australia, 172(10), 468-469.

Eckerman, A., Dowd, T., Chong, E., Nixon, L., Gray, R., \& Johnson, S. (2010). Binan Goonj: Bridging cultures in Aboriginal health (3rd ed.). Marrickville: Elsevier Australia.

Franks, T. (2011). Aboriginal cultural awareness training evaluation. Lismore: Clinical Education and Training Institute.

Fredericks, B. (2010). What health services within rural communities tell us about Aboriginal people and Aboriginal health. Rural Society, 20(1), 10-20.

Fredericks, B., Adams, K., Finlay, M., Fletcher, G., Andy, S., Briggs, L., et al. (2011). Engaging the practice of yarning in action research. Action Learning and Action Research Journal, 17(2), 7-19.

Fredericks, B. L. (2003). Us speaking about women's health: Aboriginal women's perceptions and experiences of health, well-being, identity, body and health services. (Ph.D. thesis), Central Queensland University Rockhampton.

Gorman, E. (2017). Blackfullas in ivory towers: Referenced reflections of a Bundjalung graduate nurse. Contemporary Nurse, 53(6), 691-697. https://doi.org/10.1080/10376178.2017.1409645

Graham, M. (2008). Some thoughts about the philosophical underpinnings of aboriginal worldviews. Australian Humanities Review, 45. 
Hayman, N. E., White, N. E., \& Spurling, G. K. (2009). Improving Indigenous patients' access to mainstream health services: The Inala experience. Medical Journal of Australia, 190(10), 604-606.

Henry, B. R., Houston, S., \& Mooney, G. H. (2004). Institutional racism in Australian healthcare: A plea for decency. Medical Journal of Australia, 180(10), 517-520.

Higgins, I., \& Wellington, S. (2018). Anger over Tony Abbott's Indigenous envoy role: “Haven't we been punished enough?" Retrieved from https://www.abc.net.au/news/2018-08-29/indigenousleaders-voice-anger-at-tony-abbott-envoy-role/10179436.

Hunt, J. (2013). Engaging with Indigenous Australia-Exploring the conditions for effective relationships with Aboriginal and Torres Strait Islander communities. Closing the gap clearinghouse, issues paper no.5. AIHW, Canberra: Australian Government.

Jackson, D., Power, T., Sherwood, J., \& Geia, L. (2013). Amazingly resilient Indigenous people! Using transformative learning to facilitate positive student engagement with sensitive material. Contemporary Nurse, 46(1), 105-112. https://doi.org/10.5172/conu.2013.46.1.105

Jennings, W., Bond, C., \& Hill, P. S. (2018). The power of talk and power in talk: A Systematic review of Indigenous narratives of culturally safe healthcare communication. Australian Journal of Primary Health, 24(2), 109-115. https://doi.org/10.1071/PY17082

Johnson, C. (2018). AMA endorses Uluru statement from the heart. Australian Medicine, 30(9).

King, M., Smith, A., \& Gracey, M. (2009). Indigenous health part 2: The underlying causes of the health gap. The Lancet, 374(9683), 76-85. https://doi.org/10.1016/s0140-6736(09)60827-8

Kirmayer, L. J. M. D., Dandeneau, S. P., Marshall, E. B. A., Phillips, M. K. M. A., \& Williamson, K. J. P. (2011). Rethinking resilience from indigenous perspectives. Canadian Journal of Psychiatry, $56(2), 84-91$.

Kitson, A., Marshall, A., Bassett, K., \& Zeitz, K. (2013). What are the core elements of patientcentred care? A narrative review and synthesis of the literature from health policy, medicine and nursing. Journal of Advanced Nursing, 69, 4-15.

Maher, P. (1999). A review of "traditional" aboriginal health beliefs. Australian Journal of Rural Health, 7(4), 229-236. https://doi.org/10.1111/j.1440-1584.1999.tb00462.x

McCausland, R. (2004). Special treatment-The representation of aboriginal and torres strait islander people in the media. Journal of Indigenous Policy, 16(4), 84-98.

Merritt, S. (2007). An aboriginal perspective on resilience. Aboriginal and Islander Health Worker Journal, 31(3), 10-12.

Mills, K., Sunderland, N., \& Davis-Warra, J. (2013). Yarning circles in the literacy classroom. The Reading Teacher, 67(4), 285-289.

Morgan, D. L., Slade, M. D., \& Morgan, C. M. A. (1997). Aboriginal philosophy and its impact on health care outcomes. Australian and New Zealand Journal of Public Health, 21(6), 597-601.

Nakata, M. (2002). Indigenous knowledge and the cultural interface: Underlying issues at the intersection of knowledge and information systems. IFLA, 28(5-6), 281-291.

National Aboriginal and Torres Strait Islander Health Workers Association. (2018). Cultural safety framework. Phillip, ACT: NATSIHWA.

National Aboriginal Community Controlled Health Organisations. (2016). NACCHO history. Retrieved from https://www.naccho.org.au/about-nacho/naccho-history/.

National Aboriginal Health Strategy Working Party (NAHSWP). (1989). National aboriginal health strategy. NAHSWP: Canberra.

NMBA (2018). Code of conduct for midwives. Retrieved from https://www.nursingmidwiferybo ard.gov.au/Codes-Guidelines-Statements/Professional-standards.aspx.

Oliver, S. J. (2013). The role of traditional medicine practice in primary health care within Aboriginal Australia: A review of the literature. Journal of Ethnobiology and Ethnomedicine, 9(1), 46.

Ong, S. J. (2012). Remote and urban connections-An account of caring for an Indigenous couple. Australian Nursing Journal, 20(2), 33.

Paradies, Y. (2016). Colonisation, racism and indigenous health. Journal of Population Research, 33(1), 83-96. https://doi.org/10.1007/s12546-016-9159-y 
Paradies, Y., \& Cunningham, J. (2009). Experiences of racism among urban Indigenous Australians: Findings from the DRUID study. Ethnic and Racial Studies, 32(3), 548-573. https://doi.org/10. 1080/01419870802065234

Paradies, Y., Harris, R., \& Anderson, I. (2008). The impact of racism on indigenous health in Australia and Aotearoa: Towards a research agenda. Casuarina, NT: Cooperative Research Centre for Aboriginal Health.

Poche Indigenous Health Network. (2016). Poche indigenous health network key thinkers forum: Traditional aboriginal healing and western medicine. Paper presented at the Traditional Aboriginal Healing and Western Medicine, University of Sydney.

Rallah-Baker, K. (2018a). Closing the gap from both sides. INSIGHT Australia's leading Opthalmic Magazine since 1975, 7/09/2018.

Rallah-Baker, K. (2018b). Keynote speech. Paper presented at the National Conference on Indigenous Health Workforce: Moving beyond the frontline, Brisbane, QLD.

Referendum Council. (2017). Uluru statement from the heart. Retrieved from https://www.refere ndumcouncil.org.au/sites/default/files/2017-05/Uluru_Statement_From_The_Heart_0.PDF.

Rix, E., Barclay, L., Stirling, J., Tong, A., \& Wilson, S. (2014a). Beats the alternative but it messes up your life: A qualitative study of Aboriginal people's experience of haemodialysis in rural Australia. BMJ Open, 4. https://doi.org/10.1136/bmjopen-2014-005945.

Rix, E., Barclay, L., Stirling, J., Tong, A., \& Wilson, S. (2015). The perspectives of aboriginal patients and their health care providers on improving the quality of haemodialysis services: A qualitative study. Haemodialysis International, 19(1), 80-89. https://doi.org/10.1111/hdi.12201

Rix, E., Barclay, L., \& Wilson, S. (2014b). Can a white nurse get it? "Reflexive practice" and the non-Indigenous clinician/researcher working with Aboriginal people. Journal of Rural and Remote Health, 4, 2679.

Rix, E., Moran, C., Kapeen, R., \& Wilson, S. (2016). Building cultural bridges and two-way understanding: Working with Australian Aboriginal people within mainstream renal services. Renal Society of Australasia Journal, 12, 12-17.

Sanders, W. (2018). Missing ATSIC: Australia's need for a strong Indigenous representative body In H. Howard, D. Wagner, M. Bargh, \& J. Altamirano (Eds.), The neoliberal state, recognition and Indigenous rights: New paternalism to new imaginings. Canberra: Australian National University Press.

Sheehan, N. W., Martin, G., Krysinska, K., \& Kilroy, K. (2009). Sustaining connection: A framework for Aboriginal and Torres Strait Islander community, cultural, spiritual, social and emotional wellbeing. Brisbane: Centre for Suicide Prevention Studies, University of Queensland.

Sheehan, N. W. (2011). Indigenous knowledge and respectful design: An evidence-based approach. Design Issues, 27(4), 68-80. https://doi.org/10.1162/DESi_a_00106

Sherwood, J. (2009). Who is not coping with colonization? Laying out the map for decolonization. Australasian Psychiatry, 17(s1), S24-S27. https://doi.org/10.1080/10398560902948662.

Sherwood, J. (2010). Do no harm: Decolonising aboriginal health research. (Ph.D. thesis), University of NSW, Sydney.

Sherwood, J. (2013). Colonisation-It's bad for your health: The context of aboriginal health. Contemporary Nurse, 46(1).

Sherwood, J., Lighton, S., Dundas, K., French, T., Link-Gordon, D., Smith, K., \& Anthony, T. (2015). Who are the experts here? Recognition of aboriginal women and community workers in research and beyond. AlterNative: An International Journal of Indigenous Peoples, 11(2), 177-190. https://doi.org/10.1177/117718011501100207.

Stuart, L., \& Gorman, D. (2015). The experiences of indigenous health workers enrolled in a bachelor of nursing at a regional Australian University. AlterNative: An International Journal of Indigenous Peoples, 11(1), 29-44. https://doi.org/10.1177/117718011501100103.

Stuart, L., \& Nielsen, A.-M. (2011). Two aboriginal registered nurses show us why black nurses caring for black patients is good medicine. Contemporary Nurse, 37(1), 96-101. https://doi.org/ 10.5172/conu.2011.37.1.096 
Taylor, K., \& Guerin, P. (2014). Health care and Indigenous Australians: Cultural safety in practice. South Yarra: Palgrave Macmillan.

Thackrah, R. D., \& Thompson, S. C. (2013). Refining the concept of cultural competence: Building on decades of progress. Medical Journal of Australia, 199(1), 35-38.

The Secretariat of National Aboriginal and Islander Child Care (SNAICC). (2012). Healing in practice: Promising practices in healing programs for aboriginal and torres strait islander children and families. Retrieved from https://www.snaicc.org.au/healing-in-practice-promising-practicesin-healing-programs-snaicc-2012/.

Thomson, N. (2005). Cultural respect and related concepts: A brief summary of the literature. Aust Indigenous Health Bulletin, 5(4), 1-11.

Truong, M., Paradies, Y., \& Priest, N. (2014). Interventions to improve cultural competency in healthcare: A systematic review of reviews. BMC Health Services Research, 14(1), 1-17. https:// doi.org/10.1186/1472-6963-14-99

Virdun, C., Gray, J., Sherwood, J., Power, T., Phillips, A., Parker, N., \& Jackson, D. (2013). Working together to make Indigenous health care curricula everybody's business: A graduate attribute teaching innovation report. Contemporary Nurse, 46(1), 97-104. https://doi.org/10.5172/conu. 2013.46.1.97

Westerman, T. (2004). Guest Editorial. Australian e-Journal for the Advancement of Mental Health, 3(3), 88-93. https://doi.org/10.5172/jamh.3.3.88

Westwood, B., \& Westwood, G. (2010). Aboriginal cultural awareness training: policy v. accountability-Failure in reality. Australian Health Review, 34(4), 423-429.

Wilson, K. J., Magarey, A., Jones, M., \& Mackean, T. (2016). Working at the interface in Aboriginal and Torres Strait Islander health: Focusing on the individual health professional and their organisation as a means to address health equity. International Journal for Equity in Health, 15(1), 187. https://doi.org/10.1186/s12939-016-0476-8.

Walker, M., Fredericks, B., Mills, K., \& Anderson, D. (2014). "Yarning" as a method for communitybased health research with indigenous women: the indigenous women's wellness research program. Health care for women international, 35(10), 1216-1226.

Wilson, S. (2008). Research as ceremony: Indigenous research methods. Winnipeg: Fernwood Publishing.

Liz Rix is a lecturer/academic with Gnibi College of Australian Indigenous peoples at Southern Cross University. She is also a Registered Nurse. She teaches Indigenous Health to undergraduate and postgraduate health and social work professionals. Her research interests are Indigenous Health; reflexive practice and improving the cultural competence of non-Indigenous clinicians.

Darlene Rotumah is a Bundjalung woman from Booningbah (Fingal Head, New South Wales). She is also an Indigenous Research academic with Gnibi College of Australian Indigenous peoples at Southern Cross University. She has worked in the field of Indigenous Health for over a decade as an Aboriginal Health Worker. Darlene's research interests include Aboriginal social and emotional wellbeing, and Aboriginal health workforce. 
Open Access This chapter is licensed under the terms of the Creative Commons Attribution 4.0 International License (http://creativecommons.org/licenses/by/4.0/), which permits use, sharing, adaptation, distribution and reproduction in any medium or format, as long as you give appropriate credit to the original author(s) and the source, provide a link to the Creative Commons license and indicate if changes were made.

The images or other third party material in this chapter are included in the chapter's Creative Commons license, unless indicated otherwise in a credit line to the material. If material is not included in the chapter's Creative Commons license and your intended use is not permitted by statutory regulation or exceeds the permitted use, you will need to obtain permission directly from the copyright holder.

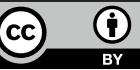

